\title{
BMJ Open Understanding public preferences and trade-offs for government responses during a pandemic: a protocol for a discrete choice experiment in the UK
}

\author{
Mesfin G Genie (D) , , Luis Enrique Loría-Rebolledo, ${ }^{1}$ Shantini Paranjothy, ${ }^{2}$ \\ Daniel Powell (D) , ${ }^{3}$ Mandy Ryan, ${ }^{1}$ Ruben Andreas Sakowsky (D) , 1 \\ Verity Watson
}

To cite: Genie MG, LoríaRebolledo LE, Paranjothy S, et al. Understanding public preferences and trade-offs for government responses during a pandemic: a protocol for a discrete choice experiment in the UK. BMJ Open 2020;10:e043477. doi:10.1136/ bmjopen-2020-043477

- Prepublication history and additional material for this paper is available online. To view these files, please visit the journal online (http://dx.doi.org/10. 1136/bmjopen-2020-043477).

Received 05 August 2020 Revised 22 0ctober 2020 Accepted 27 October 2020

D Check for updates

(c) Author(s) (or their employer(s)) 2020. Re-use permitted under CC BY-NC. No commercial re-use. See rights and permissions. Published by BMJ.

${ }^{1}$ Health Economics Research Unit, University of Aberdeen, Aberdeen, UK

${ }^{2}$ Health Data Science Research Centre, University of Aberdeen, Aberdeen, UK

${ }^{3}$ Health Psychology, University of Aberdeen, Aberdeen, UK

Correspondence to

Dr Mesfin G Genie;

mesfin.genie@abdn.ac.uk

\section{ABSTRACT}

Introduction Social distancing and lockdown measures are among the main government responses to the COVID-19 pandemic. These measures aim to limit the COVID-19 infection rate and reduce the mortality rate of COVID-19. Given we are likely to see local lockdowns until a treatment or vaccine for COVID-19 is available, and their effectiveness depends on public acceptability, it is important to understand public preference for government responses.

Methods and analysis Using a discrete choice experiment (DCE), this study will investigate the public's preferences for pandemic responses in the UK. Attributes (and levels) are based on: (1) lockdown measures described in policy documents; (2) literature on preferences for lockdown measures and (3) a social media analysis. Attributes include: lockdown type; lockdown length; postponement of usual non-urgent medical care; number of excess deaths; number of infections; impact on household spending and job losses. We will prepilot the DCE using virtual think aloud interviews with respondents recruited via Facebook. We will collect preference data using an online survey of 4000 individuals from across the four UK countries (1000 per country). We will estimate the relative importance of the attributes, and the trade-offs individuals are willing to make between attributes. We will test if respondents' preferences differ based on moral attitudes (using the Moral Foundation Questionnaire), socioeconomic circumstances (age, education, economic insecurity, health status), country of residence and experience of COVID-19.

Ethics and dissemination The University of Aberdeen's College Ethics Research Board (CERB) has approved the study (reference: CERB/2020/6/1974). We will seek CERB approval for major changes from the developmental and pilot work. Peer-reviewed papers will be submitted, and results will be presented at public health and health economic conferences nationally and internationally. A lay summary will be published on the Health Economics Research Unit blog.

\section{INTRODUCTION}

The public health response of governments to the COVID-19 pandemic has differed across

\section{Strengths and limitations of this study}

- The study will be the first discrete choice experiment (DCE) conducted to provide information on the public preferences and trade-offs for government responses during a pandemic in the UK.

- We will explore preference heterogeneity according to the respondents' sociodemographic characteristics.

- This is the first study to combine a DCE with moral foundation theory to understand how people's moral values shape preferences for government pandemic responses.

- It is not feasible to incorporate all factors that may affect the public preferences (e.g., effect on children through school closures, impact on mental health, impacts on inequalities).

- This study will be undertaken in the UK and may not be generalisable to other countries.

countries. Responses have mostly involved lockdown measures that encourage social distancing (social distancing, also called 'physical distancing,' means keeping a safe space between yourself and other people who are not from your household ${ }^{1}$ ) to slow the spread of the disease. ${ }^{23}$ The timing and strictness of these measures has differed across countries. Italy and Spain introduced early strict lockdown measures, ${ }^{45}$ while restrictions in Sweden and the Netherlands were less severe ${ }^{6}{ }^{7}$ Responses in China and Vietnam were more stringent ${ }^{89}$ due to prior experiences of responding to outbreaks of other infectious diseases, including Severe Acute Respiratory Syndrome (SARS), Middle East Respiratory Syndrome (MERS), measles and dengue. ${ }^{1011}$ Policies in the UK shifted from a more relaxed initial approach towards stricter measures as the pandemic progressed. ${ }^{12}$ As lockdowns have eased (as of 27 July 2020), we 
have seen local lockdowns introduced to deal with spikes in infection rates (e.g., Leicester (England), Melbourne (Australia) and Barcelona (Spain). ${ }^{13-15}$

The pandemic and the subsequent public health response affect both public health and the economy. ${ }^{16}$ Suppressing infections has required stringent physical distancing measures, which has had a range of direct and indirect impacts on health as well as the wider determinants of physical and mental health. ${ }^{17}{ }^{18}$ Economic impacts include increased unemployment rates and decreased household income,${ }^{19}$ with certain groups more likely to experience economic hardship. ${ }^{20-22}$ When lockdown measures are implemented the interests of different people may be in conflict. Public health responses must then balance protecting the population and healthcare system with the impact on the economy and personal freedoms. A better understanding of public preferences and how they differ across communities may help policymakers decide which interventions to deploy.

Very little is known about public preferences for lockdown policies. Previous research in Singapore and Australia conducted before the COVID-19 outbreak suggests considerable variation in preferences. Cook $e t$ $a l^{23}$ used a discrete choice experiment (DCE) to investigate public preferences for pandemic interventions for emerging infectious disease in Singapore. While respondents preferred more intense interventions, fewer deaths and lower taxes to fund public health measures, the number of infections did not affect their preferences. Respondents were willing to accept a loss of USS $\$ 370$ million at the societal level for the full set of interventions considered and a personal cost of up to USS $\$ 34$ to prevent 30 deaths, USS $\$ 70$ to prevent 80 , USS $\$ 71$ to prevent 120 and USS $\$ 98$ to prevent 180 at a national level. The value placed on a strong response (mandatory isolation and quarantine, cancelling all mass gatherings and island-wide screening), USS $\$ 74$, corresponded to the value placed on preventing 100 deaths. Johnson $e t a l^{24}$ used a DCE to explore public preferences for attributes associated with One Health strategies for emerging infectious disease prevention and control in Australia. They examined trade-offs between risk attributes (zoonotic risk or mortality) and other attributes, expressed as 'willingness to accept' extra cases of severe disease or extra deaths, to avoid compromises in other attributes. Food security was valued most highly, with respondents willing to accept the highest number of additional cases of disease or deaths, to avoid compromising food security. The next most highly valued attributes were: animal welfare; economic development; environmental health; community cohesion; personal autonomy and free trade and travel.

More recent work has used the DCE method to understand preferences and trade-offs for responses to the COVID-19 pandemic. Chorus et $a l^{25}$ elicited preferences of the Dutch adult public for relaxing lockdown. The DCE included attributes related to health, the economy, education and personal income. They found that, compared with younger people, older people are less willing to sacrifice (per fatality avoided): people with mental health problems; children at an educational disadvantage and households with an income loss. Reed $e t a l^{26}$ explored the extent to which US adults are willing to accept a greater risk spread of COVID-19 to lift social-distancing restrictions and limit the economic impact of the pandemic. They identified four preference patterns: risk minimisers who are reluctant to accept any increases in risk $(37 \%)$; those primarily concerned with time required for economic recovery, accepting increases in COVID-19 risk levels up to $16 \%$ to shorten recovery from 3 to 2 years $(26 \%)$; those who preferred delaying reopening (26\%); and those accepting COVID-19 risks beyond $20 \%$ to avoid a delay in reopening (13\%). Political affiliation, race, household income and employment status predicted preference patterns, with political affiliation being the most important predictor.

\section{Aims}

Building on these studies, we use the DCE method to estimate how people in the UK make trade-offs between features of lockdown interventions. Specifically, we explore:

- The relative importance of pandemic response features.

- Trade-offs respondents make between these features, for example, how much household spending are respondents willing to forgo to reduce excess deaths or what increase in job losses they are willing to accept for a decrease in the infection rate?

- The impact of moral attitudes on preferences.

- Preference heterogeneity based on individuals' circumstances, for example, age, gender, health status, economic security, country/region of residence, experience with COVID-19.

- Intended compliance for defined lockdown interventions and consequences.

\section{METHODS AND ANALYSIS}

\section{Overview of approach and methods}

We use an online DCE survey to elicit preferences and combine it with moral attitude data and socioeconomic characteristics to model heterogeneity. The DCE is a choice-based survey that quantifies preferences for attributes of goods or services. It assumes that goods or services (in this case pandemic responses) can be described by attributes and the levels of these attributes. ${ }^{27}$ Each respondent faces a series of hypothetical scenarios (choice sets) composed of two or more alternatives. ${ }^{28}$ In each choice set, respondents are asked to choose their preferred scenario. A DCE enables researchers to gain insight into the relative importance of each attribute and the trade-offs between these.

\section{Development of attributes and levels for the DCE}

The first stage of a DCE defines the attributes and levels. Attributes describe different lockdown scenarios (table 1) 
Table 1 Attributes and levels included in the DCE

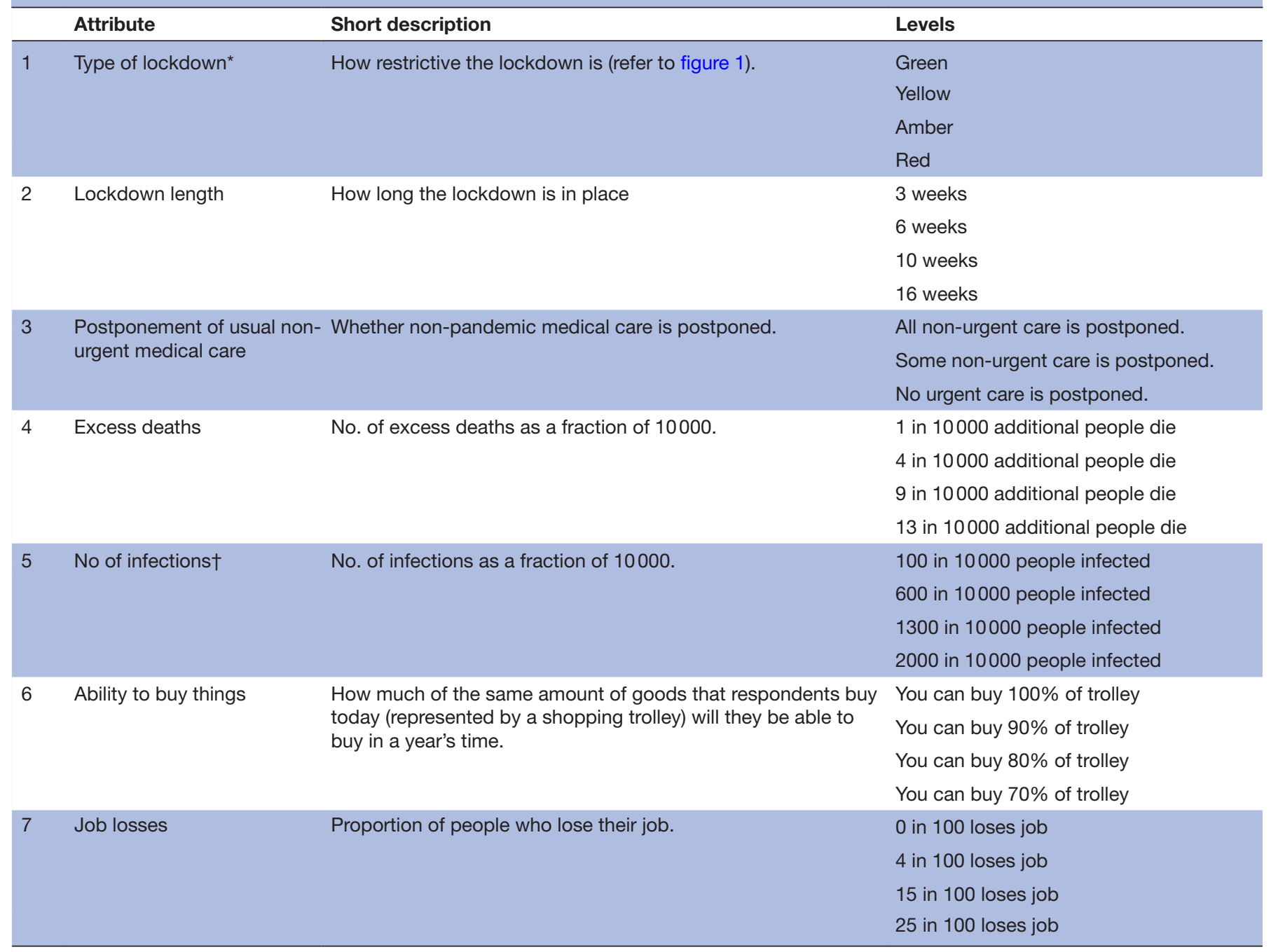

*Descriptors for each type of lockdown are presented in figure 1.

†Number of infections is linked to the excess deaths.

DCE, discrete choice experiment.

and are based on: (1) current and possible future lockdown measures from policy documents, for example, Scientific Advisory Group for Emergencies guidance, government guidance and interventions that have been observed globally in response to the COVID-19 pandemic (see table 2); (2) current literature on preferences for lockdown measures ${ }^{23}$ (i.e., from May to June 2020, we searched Google (Scholar), using the following terms

\begin{tabular}{|c|c|c|c|c|c|c|c|c|c|c|c|c|}
\hline Lockdown measures & UK & Date & France & Date & Italy & Date & Spain & Date & Sweden & Date & Netherlands & Date \\
\hline $\begin{array}{l}\text { Educational facilities } \\
\text { closed }\end{array}$ & Yes & $\begin{array}{l}\text { Mar } \\
\text { 23-Aug } 4\end{array}$ & Yes & $\begin{array}{l}\text { Mar } \\
\text { 13-Aug } 4\end{array}$ & Yes & $\begin{array}{l}\text { Mar } \\
1 \text {-Aug } 4\end{array}$ & Yes & $\begin{array}{l}\text { Mar } \\
11 \text {-Aug } 4\end{array}$ & No & - & Yes & $\begin{array}{l}\text { Ma } \\
15-\text { Aug } 4\end{array}$ \\
\hline Any gathering restrictions & Yes & $\begin{array}{l}\text { Mar } \\
\text { 23-Aug } 4\end{array}$ & Yes & $\begin{array}{l}\text { Mar } \\
4-\text { Aug } 4\end{array}$ & Yes & $\begin{array}{l}\text { Feb } \\
\text { 22-Aug } 4\end{array}$ & Yes & $\begin{array}{l}\text { Mar } \\
\text { 15-Aug } 4\end{array}$ & Yes & $\begin{array}{l}\text { Mar } \\
\text { 11-Aug } 4\end{array}$ & Yes & $\begin{array}{l}\text { Mar } \\
10-\text { Aug } 4\end{array}$ \\
\hline Stay at home order & Yes & $\begin{array}{l}\text { Mar } \\
\text { 23-Aug } 4\end{array}$ & Yes & $\begin{array}{l}\text { Mar } \\
\text { 18-Aug } 4\end{array}$ & Yes & $\begin{array}{l}\text { Mar } \\
\text { 8-Aug } 4\end{array}$ & Yes & $\begin{array}{l}\text { Mar } \\
\text { 15-Aug } 4\end{array}$ & No & - & No & - \\
\hline $\begin{array}{l}\text { All non-essential } \\
\text { businesses closed }\end{array}$ & Yes & $\begin{array}{l}\text { Mar } \\
\text { 24-Aug } 4\end{array}$ & Yes & $\begin{array}{l}\text { Mar } \\
\text { 15-Aug } 4\end{array}$ & Yes & $\begin{array}{l}\text { Mar } \\
\text { 8-Apr } 14\end{array}$ & Yes & $\begin{array}{l}\text { Mar } \\
\text { 13-Apr } 13\end{array}$ & No & - & No & - \\
\hline Travel severely limited & No & - & Yes & $\begin{array}{l}\text { Mar } \\
\text { 17-Aug } 4\end{array}$ & Yes & $\begin{array}{l}\text { Mar } \\
\text { 8-May } 4\end{array}$ & No & - & No & - & No & - \\
\hline Average duration & & $\begin{array}{l}4 \\
\text { months }\end{array}$ & & 4 months & & 5 months & & 4 months & & - & & 4 months \\
\hline
\end{tabular}


Table 3 Colour coding for type of lockdown attribute levels

\begin{tabular}{|c|c|c|c|c|}
\hline & Green & Yellow & Amber & Red \\
\hline $\begin{array}{l}\text { Stay at home (shelter in } \\
\text { place) }\end{array}$ & $\begin{array}{l}\text { Everyone (including } \\
\text { vulnerable individuals) } \\
\text { can interact with others. }\end{array}$ & $\begin{array}{l}\text { Vulnerable individuals } \\
\text { should stay home (shelter } \\
\text { in place). }\end{array}$ & $\begin{array}{l}\text { Vulnerable individuals } \\
\text { should stay at home } \\
\text { (shelter in place) and must } \\
\text { have no visitors. }\end{array}$ & $\begin{array}{l}\text { Everyone must stay at } \\
\text { home (shelter in place). }\end{array}$ \\
\hline Socialising group & $\begin{array}{l}\text { Gatherings of up to } 100 \\
\text { people. }\end{array}$ & $\begin{array}{l}\text { Gatherings of up to } 50 \\
\text { people. }\end{array}$ & $\begin{array}{l}\text { Gatherings of up to } 10 \\
\text { people. }\end{array}$ & $\begin{array}{l}\text { No gatherings beyond } \\
\text { own household (own } \\
\text { bubble). }\end{array}$ \\
\hline $\begin{array}{l}\text { Schools and youth } \\
\text { activities: }\end{array}$ & Open & Open & Closed & Closed \\
\hline $\begin{array}{l}\text { Businesses (eg, shops) } \\
\text { can operate under: }\end{array}$ & Limited social distancing & $\begin{array}{l}\text { Moderate social } \\
\text { distancing, operate at } \\
\text { reduced capacity }\end{array}$ & $\begin{array}{l}\text { Strict social distancing, } \\
\text { operate at minimal } \\
\text { capacity }\end{array}$ & Closed \\
\hline
\end{tabular}

and combinations of them: 'COVID-19', 'coronavirus', 'DCE', 'pandemic', and 'infectious disease') and (3) a social media analysis (see online supplementary material (OSM-1)).

We chose attributes based on (1) and (2) that described the health and wider economic context of the COVID-19 pandemic and lockdown measures. Then we used social media analysis to gain insight into how these attributes were discussed in the public domain. We conducted localised searches for tweets that contained phrases or words that could be used to describe the attributes. We generated a sentiment analysis ${ }^{29}{ }^{30}$ from the tweets to illustrate how people were construing these words when related to the attributes. This provided insight as to what was important to the general public and how it was being talked about. We informed the attribute levels using estimates and, if available, evidence of the effects from the pandemic and lockdown across different countries.

The attributes and levels are:

\section{Type of lockdown}

Lockdowns comprise measures across a number of dimensions (business operation, travel, stay at home orders, etc). We compile these into types of lockdown that vary in the strictness of restrictions. We describe these using colour coding (table 3). We include four lockdown types (from least to most restrictive): green, yellow, amber and red (figure 1). Each level is based on ongoing policy discussion during the COVID-19 pandemic and is analogous to the phased approach used in several countries (e.g., England, Scotland, USA, New Zealand).

\section{Lockdown length}

The number of weeks the lockdown will be in effect. This attribute had four levels: 3 weeks; 6 weeks; 10 weeks and 16 weeks.
Postponement of usual non-urgent medical care

Governments around the world have cancelled usual medical care to deal with staff shortages and help the healthcare system respond to an expected increase in patients. This attribute is particularly relevant in the UK context and is under the scope of the government. For example, the Scottish government cancelled routine procedures in $2020 .^{31}$ Further, nearly a million appointments for mammograms have been missed in the UK due to the COVID-19 pandemic. ${ }^{32}$ This and the extra capacity built in the NHS with the Nightingale hospitals in England and the Louisa Jordan Hospital in Glasgow means that this attribute is particularly relevant for providing policy advice. This attribute has three levels: all non-urgent, non-pandemic-related procedures postponed; some non-urgent procedures postponed and all procedures continue as scheduled.

\section{Excess deaths}

This attribute refers to the number of excess deaths that occur in a pandemic year compared with historical annual averages; this includes both pandemic and nonpandemic related deaths. Approximately 600000 people die in the UK each year. It is expected at least 50000 more people in the UK will die in 2020 than in previous years (an $8 \%$ increase $(50000 / 600000))$. The expected increases in historical annual deaths for other European countries are Germany 1\%, Sweden 4\%, France 5\% and Spain $8 \%$. This attribute has four levels, increases of: $1 \%$ (1 in 10000 additional people die), $5 \%$ (4 in 10000 additional people die), $10 \%$ (9 in 10000 additional people die) and $15 \%$ (13 in 10000 additional people die) in the annual expected UK deaths.

We also report the number of infections as a complement to the excess deaths, which refers to the number of people infected as a fraction of 10000 people. To avoid unrealistic combinations for each excess death level we 


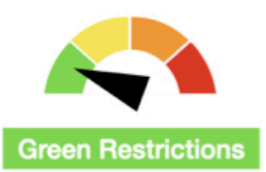

Shelter: everyone can interact with others.

Socialising: gatherings of up to 100 people.

Non-essential trips: are allowed.

Schools and youth activities: are open.

Non-essential businesses: operate under limited social distancing.

Outdoor leisure activities: are allowed.

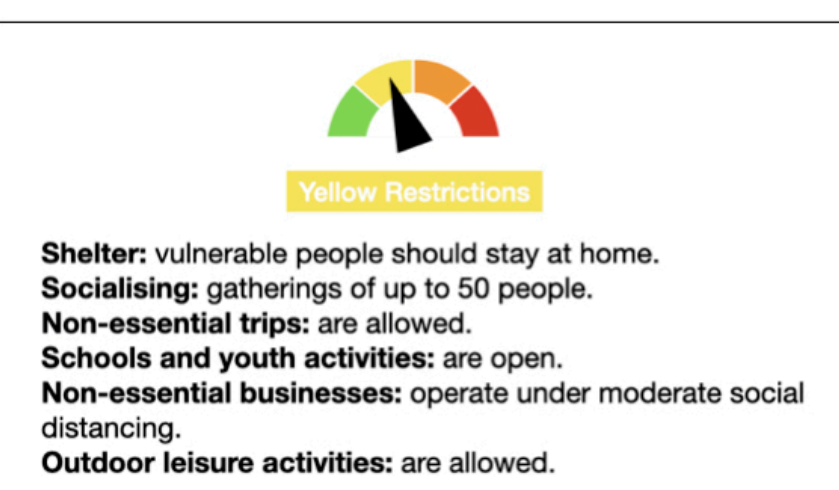

Shelter: vulnerable people should stay at home. Socialising: gatherings of up to 50 people.

Non-essential trips: are allowed.

Schools and youth activities: are open. distancing.

Outdoor leisure activities: are allowed.

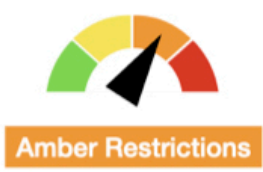

Shelter: vulnerable people stay at home with no visitors. Socialising: gatherings of up to 10 people. Non-essential trips: should be minimised. Schools and youth activities: are closed. Non-essential businesses: operate under strict distancing with limited capacity.

Outdoor leisure activities: are allowed.

Figure 1 Lockdown levels for the 'type of lockdown' attribute .

\section{$\longrightarrow$ \\ Red Restrictions}

Shelter: everyone should stay at home with no visitors. Socialising: no gatherings beyond your own household. Non-essential trips: not allowed.

Schools and youth activities: are closed.

Non-essential businesses: remain closed.

Outdoor leisure activities: are not allowed.

pandemic. The attribute has four levels of ability to afford of: $70 \%, 80 \%, 90 \%$ and $100 \%$ of of the trolley.

\section{Job losses}

OECD projections indicate that the COVID-19 crisis will result in the highest peak in unemployment across OECD economies since the Great Depression, with the unemployment rate forecast to be at $9.4 \%$ across OECD countries at the end of 2020 in the most optimistic scenario, and still at $7.7 \%$ the year after. ${ }^{34}$ This attribute refers to the proportion of people who will lose their jobs as a result of the lockdown. The attribute has four levels: 0 in 100 loses job, 4 in 100 loses job, 15 in 100 loses job and 25 in 100 loses job.

\section{Experimental design and construction of choice sets}

These attributes and levels are combined to create lockdown scenarios and paired into choice sets of two scenarios. We used NGENE software (ChoiceMetrics) to generate a 24 choice tasks D-efficient design with noninformative (null) priors and allowing estimation of nonlinear effects of attributes. ${ }^{36}$ Respondents will be allocated to one of three blocks, so they will neither all face the same choice tasks, nor in the same order. The design was based on the main effects only (ie, without interactions). The 24 choice sets were blocked into three sets of eight choice tasks to reduce respondents' burden. The order of choice tasks within each block will be randomised. 


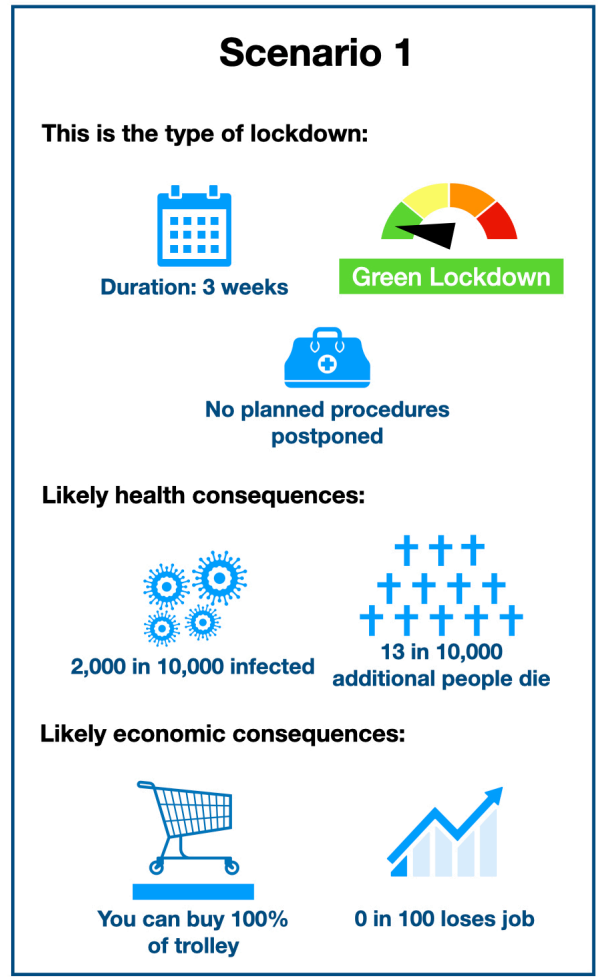

Figure 2 An example of a choice task.

Scenario attributes will be presented using visual aids to ease comprehension. Figure 2 shows an example choice task.

\section{Questionnaire design}

The online survey platform enables us to explain attributes using pop-ups of additional information and animated images. We will include questions to gauge understanding of the attributes' levels. We also include an additional repeated choice task as a consistency check, and we will ask respondents how likely they are to comply with the chosen scenario. The compliance information will be used to understand whether people's moral attitudes affect compliance with the chosen scenario of the repeated choice task. There is some evidence of a positive correlation between high scores in the binding moral foundations and an intent to defy social distancing rules. ${ }^{37}$ Further, the compliance data will be used to explore whether respondents who are more likely to comply with the selected scenario have a specific pattern of preferences. We will also explore the impact of socioeconomic characteristics, experiences with COVID-19 and views on government handling on compliance.

We include the Moral Foundation Questionnaire (MFQ20) to assess the role of moral attitudes in predicting preferences. ${ }^{38}$ This instrument is based on Moral Foundations Theory, which evaluates the normative attitudes on which people base their moral thinking across five dimensions. Moral Foundations Theory divides these five categories into two 'individualising foundations' (Care/ Harm and Fairness/Reciprocity) and three 'binding foundations' (In-group/Loyalty; Authority/Respect; and

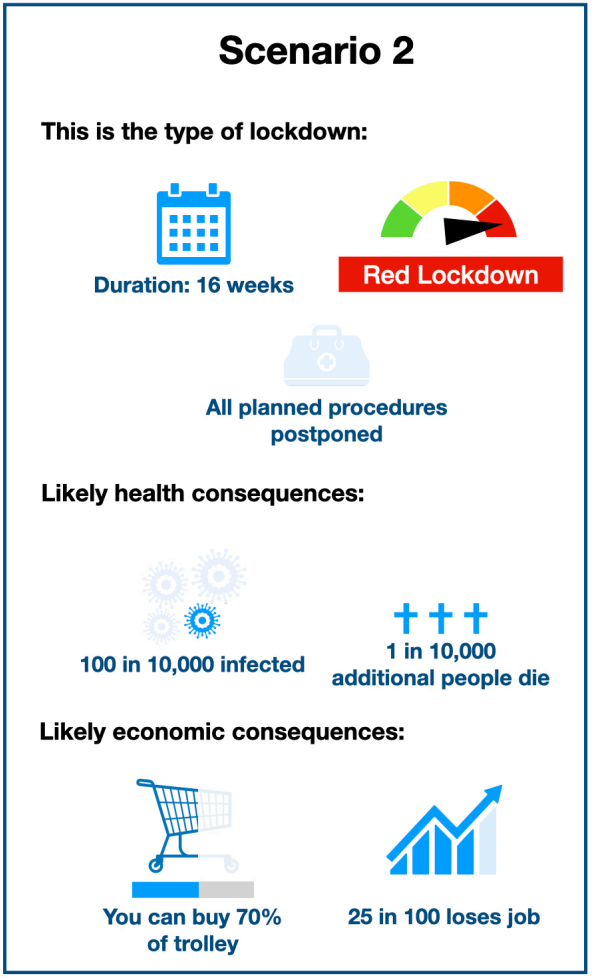

Purity/Sanctity) ${ }^{39}$ The MFQ20 consists of 20 questions and statements for which respondents indicate their agreement or disagreement on a 6-point Likert Scale. The questionnaire includes four questions or statements for each moral foundation. Based on their responses, respondents are assigned score values for each dimension running from 0 to 20 . The internal and external validity of the questionnaire has been demonstrated..$^{38}$

The survey instrument will also collect information on respondents' socio-demographic characteristics (age, sex, education, ethnicity, economic insecurity, health status), country of residence and experience of COVID-19. These observable characteristics will be used to characterise preference heterogeneity. To ensure comparability of our sample with the UK general population, where applicable questions will be based on questions underlying existing national statistics (e.g., the UK census, Office for National Statistics-Labour Force Survey).

\section{Preliminary developmental work}

We have conducted opportunistic developmental work. Virtual think-aloud interviews were conducted using MS teams with colleagues $(n=10)$ and members of our Stakeholder Advisory Group ( $\mathrm{SAG}, \mathrm{n}=3$ ). While thinkaloud studies have been shown to be informative when understanding responses to DCEs ${ }^{40}$ and interpreting the descriptors for attributes and levels, ${ }^{41}$ their virtual application is novel. Participants were asked to share their computer screen with the interviewers and to think aloud while responding to the survey. Based on these interviews, we made a number of adjustments to attribute wording, ordering and the format of attribute levels 
(see online supplementary material 2 (OSM-2) for more information).

\section{Identifying and recruiting participants for developing the questionnaire}

We will further test the DCE survey with members of the general population, using think-aloud video interviews. Participants will be recruited using social media adverts, using Facebook (see online supplementary material 3 (OSM-3) ). We will target as wide an audience in the UK as possible to minimise selection bias. Participants who express an interest will be sent an invitation email with information about the think-aloud interview and, if still interested, can arrange an interview. Participants will be sent the survey link and asked to think aloud as they complete the survey while the researcher listens and takes notes. Participants will be encouraged to express their thoughts on the survey clarity, length and structure and the format of the questions. Verbal consent will be taken prior to the start of the interview. Participants will be compensated with a £20 Amazon voucher for their time, which will be sent to them electronically after the interview. The survey text and layout will be changed iteratively during the think aloud phase to improve understanding of the task. We will seek approval for major changes from the University of Aberdeen's College Ethics Research Board (CERB).

\section{Identifying and recruiting participants for the quantitative pilot and main survey}

The pilot study will assess if parameter estimates are in line with a priori expectations. Should the data suggest face validity problems we will make further amendments to the questionnaire and conduct further piloting. Participants for the pilot and main DCE study will be identified and recruited by the survey company Qualtrics. The questionnaire will be administered as an online survey to the general public recruited from the UK (England, Scotland, Wales and Northern Ireland) with quotas based on age and gender to ensure a representative sample. Qualtrics will also arrange compensation to participants. More information on further consent related terms and conditions for Qualtrics can be found in the link: https://www. qualtrics.com/privacy-statement/ .

\section{Sample size}

Sample size for the think aloud virtual interviews will be determined by saturation point; this is expected to require approximately $15-20$ interviews. ${ }^{42}$

The sample size for the DCE survey is calculated using Louviere's formula for choice proportions to approximate the minimum sample size. ${ }^{43}$ Given a baseline choice probability of $50 \%$, an accuracy level of $90 \%$, a confidence level of $95 \%$ and eight choice tasks per respondent, we require a minimum of 49 respondents. We will recruit 50 individuals from each of the four UK countries to pilot the DCE questionnaire and statistical model. Given we aim to explore heterogeneity of preferences in the main study, we thus decide to be conservative and to have a total of 1000 respondents per country ( $\mathrm{n}=4000$ in total).

\section{Data analysis}

The choice data will be analysed using variants of the multinomial logit (MNL) model. ${ }^{44}$ From the DCE questions, we observe that respondents will choose one intervention scenario from two scenarios presented in each choice task. We assume that, in each choice task, respondents choose the alternative that provides them with the highest utility. The link between observed choices and changes in the attributes is made possible by the random utility maximisation (RUM) framework. ${ }^{45}$ The utility, $U$, that respondent $n$ obtains from choosing intervention $j$ in a choice task $t$ can be decomposed into two parts: a deterministic part, $V$, which is observable to the researcher (i.e., based on the attributes included in the DCE), and a random component, $\varepsilon$, which is unobserved.

In mathematical terms, the RUM framework is described as:

$$
\begin{aligned}
\mathrm{U}_{\mathrm{njt}} & =\mathrm{V}_{\mathrm{njt}}+\varepsilon_{\mathrm{njt}} \\
V_{n j t} & =\sum_{k} \beta_{k} X_{k j t}
\end{aligned}
$$

where $n, j, t$ and $k$ are subscripts respectively for the respondents $(n=1, \ldots, N)$, the pandemic response interventions/alternatives $(j=1, \ldots \mathrm{J})$, the choice tasks $(t=1, \ldots, \mathrm{T})$, and the attributes $(k=1, \ldots, \mathrm{K})$. The systematic part $(\mathrm{V})$ is typically described as a linear combination of both respondent's preferences $\left(\beta_{k}\right)$ and attributes' levels $\left(X_{k}\right)$. The stochastic part is unobserved, and assumptions should be made about its nature. The probability that respondents will choose scenario A over scenario B in the choice task can be calculated if the distribution of $\varepsilon$ is specified. The typical assumption about $\varepsilon$ is that it is identically and independently distributed as type 1 extreme (EV1). Under this assumption, the respondents' choices can be analysed using logit-based models such as MNL model. In the MNL model, the probability of choosing an alternative $\left(P_{n i t}\right)$ depends on its relative utility (i.e., the larger the utility compared with the other pandemic response strategies on offer the more likely the alternative is to be selected).

In DCEs, the systematic component (V) is a function (typically linear and additive) of the attributes and levels included in the study design. The regression coefficients (and their associated $t$ statistics) provide information on whether a change in an attribute's level has a significant effect on an intervention's utility, and the direction of any effect. The ratio of the regression coefficients, known as the Marginal Rate of Substitution (MRS), shows the tradeoffs that respondents make between any two attributes e.g. how much household spending are respondents willing to forgo to reduce excess deaths or what increase in job losses they are willing to accept for a decrease in the infection rate. Trade-offs (MRS) will be estimated for all relevant attributes' levels and confidence intervals calculated. $^{46}$ 
We will explore observed heterogeneity according to moral attitudes (using MFQ 20) and socioeconomic characteristics for example, age, gender, health status, economic insecurity, country of residence and experience with the COVID-19 pandemic. While some covariates such as sex, ethnicity, country of residence, education, and income will be included as categorical variables, others such as age, household size will be included either as continuous or categorical. We will use mixed logit (MXL) models to test for unobserved preference heterogeneity, treating responses as a function of choice alternatives and individual characteristics.

The socioeconomic characteristics will be analysed by interacting them with the attributes in the MNL and MXL model specifications. We will start from the MNL model, interacting socioeconomic variables with the attributes to account for observed preference heterogeneity. We will then interact the socioeconomic variables with the mean of the random parameters in the MXL framework to account for both observed and unobserved preference heterogeneity. We will also test latent class models, using socioeconomic characteristics as covariates of class membership. Given we cannot observe individuals' moral attitudes, but rather indicators of moral attitudes, we will treat them as latent variables. To explore differences in preferences between the five dimensions of moral values, we will use a hybrid choice model with each of the parameters interacting with each of the dimensions in turn. Choice of the final parsimonious model will be determined using measures of goodness of fit for example, log-likelihood, McFadden's $\mathrm{R}^{2}$, Ben-Akiva-Lerman $\mathrm{R}^{2}$, the Akaike and Bayesian information criteria.

\section{ENSURING IMPACT}

We have established a Stakeholder Advisory Group (SAG) to advise on the development of the survey instrument and dissemination and to maximise the policy contribution of this research. Our SAG has representation from the four devolved nations: Neil Craig, Acting Team Head Evaluation, Public Health Scotland; Professor Mark Bellis, Director of Policy and International Health, Wales; Professor Hugo van Woerden, Director of Public Health and Medical Director, Belfast and Brian Ferguson Chief Economist, Public Health England; Shona Christie, Scottish Government Chief Scientist Office Public Engagement Group. This group will be consulted throughout the project. Virtual sessions will be organised when developing the survey to ensure policy relevance and to discuss our findings with the aim of translating the findings into messages for policy.

\section{PATIENT AND PUBLIC INVOLVEMENT}

We have a public representative who is a member of the Scottish Government Chief Scientist Office Public Engagement Group (Shona Christie) on our SAG. She will advise on the development of the DCE survey and reporting of results. We will work with the Public Engagement in Research Unit (PERU) at the University of Aberdeen to disseminate results to the public. PERU has a dedicated programme for the active engagement of researchers with the public. Our research will be registered with the Research Registry-this is a publicly accessible database.

\section{ETHICS AND DISSEMINATION}

Ethical approval was obtained from the University of Aberdeen's CERB (Reference CERB/2020/6/1974). Following the developmental work, the research team will seek CERB approval for all amendments to the Protocol, questionnaire or other study documents. Results will be disseminated via webinars to the public health community (informed by our Stakeholder Group) and to the academic community (via journals). Project information will be reported on the publicly available HERU website, and we will use HERU's Blog and social media accounts to disseminate key findings. Findings from the study will be presented at national/international conferences and peer-reviewed journals. Authorship policy will follow the recommendations of International Committee of Medical Journal Editors; http://www.icmje.org/recommendations/browse/roles-and-responsibilities/definingthe-role-of-authors-and-contributors.html

\section{Consent}

For the questionnaire development, the researcher will confirm eligibility and take verbal consent before starting the interview. Qualtrics will confirm eligibility for the main study. Consent for participants will be sought as part of the survey prior to the data collection questions.

\section{Twitter Mesfin G Genie @mesfin_genie}

Acknowledgements We thank colleagues for their comments on the study design and questionnaire. We also thank Dr Dwayne Boyers for his internal review of the project protocol and Professor Vikki Entwistle for comments on the protocol.

Contributors The writing of the protocol was led by the Health Economics Research Unit (HERU) team (MGG, MR, RAS, LEL-R and VW). Comments were provided by SP and DP.

Funding This project is supported by the Scottish Government Health and Social Care Directorate and the University of Aberdeen.

Competing interests None declared.

Patient consent for publication Not required.

Provenance and peer review Not commissioned; externally peer reviewed.

Supplemental material This content has been supplied by the author(s). It has not been vetted by BMJ Publishing Group Limited (BMJ) and may not have been peer-reviewed. Any opinions or recommendations discussed are solely those of the author(s) and are not endorsed by BMJ. BMJ disclaims all liability and responsibility arising from any reliance placed on the content. Where the content includes any translated material, BMJ does not warrant the accuracy and reliability of the translations (including but not limited to local regulations, clinical guidelines, terminology, drug names and drug dosages), and is not responsible for any error and/or omissions arising from translation and adaptation or otherwise.

Open access This is an open access article distributed in accordance with the Creative Commons Attribution Non Commercial (CC BY-NC 4.0) license, which permits others to distribute, remix, adapt, build upon this work non-commercially, and license their derivative works on different terms, provided the original work is properly cited, appropriate credit is given, any changes made indicated, and the use is non-commercial. See: http://creativecommons.org/licenses/by-nc/4.0/. 


\section{ORCID iDs}

Mesfin G Genie http://orcid.org/0000-0002-1744-4666

Daniel Powell http://orcid.org/0000-0003-4995-6057

Ruben Andreas Sakowsky http://orcid.org/0000-0002-6893-9220

Verity Watson http://orcid.org/0000-0002-3824-5076

\section{REFERENCES}

1 CDC. Social distancing, 2020. Available: https://www.cdc.gov/ coronavirus/2019-ncov/prevent-getting-sick/social-distancing.html

2 Hale T, Webster S, Petherick A, et al. Oxford COVID-19 government response Tracker. Blavatnik School of Government, 2020. www.bsg. ox.ac.uk/covidtracker

3 Colbourn T. COVID-19: extending or relaxing distancing control measures. Lancet Public Health 2020;5:e236-7.

4 Chiara B, Marcello A, Mesfin G G, et al. The COVID-19 pandemic in Italy: policy and technology impact on health and non-health outcomes. Health Policy Technol 2020:hlpt.2020.08.019.

5 Henríquez J, Gonzalo-Almorox E, García-Goñi M, et al. The first months of the COVID-19 pandemic in Spain. Health Policy Technol 2020.

6 Kavaliunas A, Ocaya P, Mumper J, et al. Swedish policy analysis for Covid-19. Health Policy and Technology 2020:j.hlpt.2020.08.009.

7 Hoekman LM, Smits MMV, Koolman X. The Dutch COVID-19 approach: regional differences in a small country.: the Dutch COVID-19 approach. Health Policy Technol 2020:443.

8 Qiu Y, Chen X, Shi W. Impacts of social and economic factors on the transmission of coronavirus disease 2019 (COVID-19) in China. J Popul Econ 2020;33:1127-72.

9 Nguyen NPT, Hoang TD, Tran VT, et al. Preventive behavior of Vietnamese people in response to the COVID-19 pandemic. PLoS One 2020;15:e0238830.

10 AlTakarli NS. China's Response to the COVID-19 Outbreak: A Model for Epidemic Preparedness and Management. Dubai Medical Journal 2020;3:44-9.

11 Gavi. Here are four ways Vietnam has managed to control COVID-19. Available: https://www.gavi.org/vaccineswork/here-are-four-waysvietnam-has-managed-control-covid-19 [Accessed Oct 2020].

12 IHME. COVID-19 projections, United Kingdom, 2020. Available: https://covid19.healthdata.org/united-kingdom [Accessed 5 May 2020].

13 BBC. Coronavirus: why has Leicester had a spike of coronavirus? 2020. Available: https://www.bbc.co.uk/news/health-53235709

14 BBC. Coronavirus in Australia: Melbourne returns to lockdown as cases surge, 2020. Available: https://www.bbc.co.uk/news/worldaustralia-53319554

15 Time. Spain is facing a second wave of coronavirus outbreaks, 2020. Available: https://time.com/5871218/spain-coronavirus-cases/

16 Eubank S, Eckstrand I, Lewis B, Ferguson NM, Laydon D, NedjatiGilani G, et al. Commentary on Ferguson, et al., "Impact of Nonpharmaceutical Interventions (NPIs) to Reduce COVID-19 Mortality and Healthcare Demand". Bull Math Biol 2020;82:52.

17 Galea S, Merchant RM, Lurie N. The mental health consequences of COVID-19 and physical distancing: the need for prevention and early intervention. JAMA Intern Med 2020;180:817-8.

18 Fiorillo A, Gorwood P. The consequences of the COVID-19 pandemic on mental health and implications for clinical practice. European Psychiatry 2020;63.

19 Coibion O, Gorodnichenko Y, Weber M. The cost of the covid-19 crisis: Lockdowns, macroeconomic expectations, and consumer spending (NO. w27141. National Bureau of Economic Research, 2020.

20 Chetty R, Friedman JN, Hendren N. How did covid-19 and stabilization policies affect spending and employment? a new realtime economic tracker based on private sector data (NO. w27431. National Bureau of Economic Research, 2020.

21 Josephs L. American Airlines Cutting International Summer Schedule by $60 \%$ as Coronavirus Drives Down Demand. CNBC News, 2020. Available: https://www.cnbc.com/2020/04/02/coronavirus-updateamerican-airlines-cuts-summer-international-flights-by-60percentas-demand-suffers.html
22 Sobieralski JB. COVID-19 and airline employment: insights from historical uncertainty shocks to the industry. Transportation Research Interdisciplinary Perspectives 2020;5:100123.

23 Cook AR, Zhao X, Chen MIC, et al. Public preferences for interventions to prevent emerging infectious disease threats: a discrete choice experiment. BMJ Open 2018;8:e017355.

24 Johnson J, Howard K, Wilson A, et al. Public preferences for one health approaches to emerging infectious diseases: a discrete choice experiment. Soc Sci Med 2019;228:164-71.

25 Chorus C, Sandorf ED, Mouter N. Diabolic dilemmas of COVID-19: An empirical study into Dutch society's trade-offs between health impacts and other effects of the lockdown, 2020. Available: https:// mpra.ub.uni-muenchen.de/100575/

26 Reed S, Gonzalez JM, Johnson FR. Willingness to accept tradeoffs among COVID-19 cases, Social-Distancing restrictions, and economic impact: a nationwide US study. Value Health 2020;23:1438-43.

27 Lancaster KJ. A new approach to consumer theory. J Polit Econ 1966;74:132-57.

28 Ryan M, Gerard K, Amaya-Amaya M. Using discrete choice experiments to value health and health care. 11. Springer Science \& Business Media, 2007.

29 Wong CA, Sap M, Schwartz A, et al. Twitter sentiment predicts Affordable care act marketplace enrollment. J Med Internet Res 2015;17:e51.

30 Agarwal A, Xie B, Vovsha I, et al. Sentiment analysis of Twitter data. Proceedings of the Workshop on Language in Social Media, 2011: 30-8. https://dl.acm.org/doi/

31 NHS Performs. Cancelled operations. Available: https://www. nhsperforms.scot/hospital-data/indicator-hospital?hospitalid=3\& indicatorid=28 [Accessed Oct 2020].

32 Breast Cancer Now. Almost one million women in UK miss vital breast screening due to COVID-19. Available: https:// breastcancernow.org/about-us/media/press-releases/almost-onemillion-women-in-uk-miss-vital-breast-screening-due-covid-19 [Accessed Oct 2020].

33 Meyerowitz-Katz G, Merone L. A systematic review and metaanalysis of published research data on COVID-19 infection fatality rates. Int $J$ Infect Dis 2020;101:138-48.

34 OECD. OECD employment outlook 2020: worker security and the COVID-19 crisis. Paris: OECD Publishing, 2020.

35 McKibbin WJ, Fernando R. The global Macroeconomic impacts of COVID-19: seven scenarios. SSRN Journal 2020.

36 Rose JM, Bliemer MCJ. Sample size requirements for stated choice experiments. Transportation 2013;40:1021-41.

37 Graham A, Cullen FT, Pickett JT, et al. Faith in Trump, moral foundations, and social distancing Defiance during the coronavirus pandemic. Socius 2020;6:237802312095681.

38 Graham J, Nosek BA, Haidt J, et al. Mapping the moral domain. J Pers Soc Psychol 2011;101:366-85.

39 Haidt J, Graham J. When morality opposes justice: Conservatives have moral Intuitions that Liberals may not recognize. Soc Justice Res 2007;20:98-116.

40 Ryan M, Watson V, Entwistle V. Rationalising the 'irrational': a think aloud study of discrete choice experiment responses. Health Econ 2009;18:321-36.

41 Burton CD, Entwistle VA, Elliott AM, et al. The value of different aspects of person-centred care: a series of discrete choice experiments in people with long-term conditions. BMJ Open 2017;7:e015689.

42 Francis JJ, Johnston M, Robertson C, et al. What is an adequate sample size? Operationalising data saturation for theory-based interview studies. Psychol Health 2010;25:1229-45.

43 Louviere JJ, Hensher DA, Swait JD. Stated choice methods: analysis and applications. Cambridge university press, 2000.

44 Train KE. Discrete choice methods with simulation. Cambridge university press, 2009.

45 McFadden D, Zarembka P. Frontiers in econometrics. conditional logit analysis of qualitative choice behaviour, 1974: 105-42.

46 Hole AR. A comparison of approaches to estimating confidence intervals for willingness to pay measures. Health Econ 2007;16:827-40. 